\title{
Development of a Method for Detection of the Biocontrol Agent Penicillium oxalicum Strain 212 by Combining PCR and a Selective Medium
}

\author{
I. Larena and P. Melgarejo, Departamento de Protección Vegetal, Instituto Nacional de Investigación y Tecnología \\ Agraria y Alimentaria (INIA), Madrid, Spain
}

\begin{abstract}
Larena, I., and Melgarejo, P. 2009. Development of a method for detection of the biocontrol agent Penicillium oxalicum strain 212 by combining PCR and a selective medium. Plant Dis. 93:919-928.

The registration of biological control agents requires the development of monitoring systems to detect and quantify the agent in the environment. Penicillium oxalicum strain 212 (PO212) is being developed for the control of tomato pathogens. In this study, we demonstrated that PO212 was more effective for controlling Fusarium oxysporum f. sp. lycopersici in tomato plants than 13 other $P$. oxalicum strains. A new semiselective medium was developed as a preliminary screen for $P$. oxalicum from soil. This semiselective medium was a modified Fusarium selective medium that contained $0.006 \mathrm{~g}$ of nystatin per liter. The growth of $P$. oxalicum strain 212 was not inhibited on this medium, but it did inhibit the growth of 11 fungal species. Specific identification of the biocontrol strain and its quantification were achieved using a polymerase chain reaction with a strain-specific pair of primers (POITS1F/POITS2R1) and dilution plating. This primer set differentiated the biocontrol strain from 13 other strains of $P$. oxalicum. There were differences in the nucleotide sequences of the internal transcribed spacer (ITS) regions of the ribosomal DNA of 25 strains of $P$. oxalicum and those of PO212. Based on the differences in the nucleotide sequences of the ITS regions in rDNA of PO212 and other $P$. oxalicum strains, a relationship between the nucleotide sequences in the ITS region and biocontrol efficacy is postulated.
\end{abstract}

In agriculture, the control of pests and diseases is achieved mainly by spraying crops with chemical pesticides (5). New restrictions on the application of these chemicals and environmental considerations have led to increased interest in the use of biological agents for disease control in crops $(5,33)$.

For many years, we have been investigating the biocontrol efficacy of a conidial suspension of strain 212 of Penicillium oxalicum Currie \& Thom. (PO212) in growth chamber, glasshouse, and openfield experiments. In this regard, we reported that an application of PO212 to tomato seedlings 7 days before transplanting resulted in a 20 to $80 \%$ reduction in the incidence of Fusarium wilt of tomato by inducing resistance $(9,10,12)$. We reported also that application of $P$. oxalicum reduced the incidence of other tomato diseases that were caused by Verticillium spp., Botrytis cinerea, Phytophthora parasitica, and $P$. infestans $(28,29,41)$. We have shown also that an application of $P$. oxalicum alone or in combination with the fumigant

Corresponding author: P. Melgarejo

E-mail: melgar@inia.es

Accepted for publication 11 May 2009.

doi:10.1094/PDIS-93-9-0919

(c) 2009 The American Phytopathological Society dazomet can reduce the incidence of other wilt diseases, such as those caused by Fusarium oxysporum f. sp. niveum and $F$. oxysporum $\mathrm{f}$. sp. melonis, in watermelons and melons (A. De Cal et al., unpublished results), as well as powdery mildew caused by Podosphaera aphanis in strawberry plants (14).

The registration of a biological control agent (BCA) requires the development of monitoring methods for its environmental detection and quantification. However, the selectivity of the monitoring method must be at the strain level because many BCAs belong to species that are common inhabitants in plants (31). In order to establish the ideal environmental conditions for applying a BCA, it is important also to assess the impact of the formulation or preparation and the method of application on its ecological fitness (33).

Conventional methods for the environmental detection and identification of fungi have relied mainly on the isolation of individual strains in culture and the subsequent characterization of morphological traits. The utility of these methods is limited because they are time-consuming and laborious, and they require considerable expertise to clearly differentiate between closely related species. In order to overcome these limitations, advanced molecular methods, in which nucleic acids are extracted and then amplified by polymerase chain reaction (PCR), have been developed. Compared with other diagnostic methods, these techniques have the advantage of not always requiring the target organism to be cultured before detection, and being highly sensitive and specific (25). These diagnostic assays can be developed by exploiting sequence polymorphisms within the internal transcribed spacers (ITS1 and ITS2) of the ribosomal DNA (rDNA), unique sequences in mitochondrial DNA, cloned restriction fragments from genomic DNA, or sequenced fragments from random amplified polymorphic DNA (RAPD) $(1,4)$.

Although dilution plate methods significantly limit the quantitation of soil microorganisms, the use of selective media that enable the estimation of relative changes in abundance has greatly increased our understanding of the ecology of fungi in soil (2). Previously, we developed a semiselective medium, which we called a modified Nash and Snyder medium (MNSM), for detecting and enumerating colonies of $P$. oxalicum from soil and tomato roots $(13,34)$. Unfortunately, the use of MNSM does not distinguish PO212 in commercial fields and glasshouse soils from other indigenous isolates of $P$. oxalicum that may not be useful as BCAs.

Here, we sought to establish a simple and reliable method to identify PO212 unequivocally in natural pathosystems. For this purpose, we characterized and analyzed differences between the nucleotide sequences of the ITS of the rDNA from 14 strains of $P$. oxalicum. We demonstrated that a combination of dilution plating on semiselective medium and specific PCR analysis permitted us to identify and quantify PO212 in natural pathosystems. We examined also the genetic variation within 25 strains of $P$. oxalicum in order to establish whether this variation was related to the geographical origin, the hosts from which they were isolated, or their biocontrol efficacy.

\section{MATERIALS AND METHODS}

Fungal isolates. The fungal isolates that were used in this study, listed in Tables 1 and 2, originated from different geographical regions, habitats, and culture collections. The isolate PO212 (ATCC 201888) was identified originally from soil samples in Spain (11). All isolates were stored as conidial suspensions in $20 \%$ glycerol at $-80^{\circ} \mathrm{C}$ for long-term storage, and in potato dextrose agar (PDA) (Difco Laboratories, 
Detroit, MI, USA) at $4^{\circ} \mathrm{C}$ for short-term storage. For conidial and mycelial production, all isolates were cultured on PDA plates at $22^{\circ} \mathrm{C}$ in the dark. The isolate of Fusarium oxysporum f. sp. lycopersici race 2 (ATCC 201829), which was obtained from a tomato plant in southern Spain, was stored at $4^{\circ} \mathrm{C}$ in tubes that contained sterile sand, and was grown on Czapek Dox Agar (CDA) (Difco) in the dark at $25^{\circ} \mathrm{C}$ to produce mycelia. The virulence of $F$. oxysporum $\mathrm{f}$. sp. graded as type 3 according to Pineau's scale (75\% of plants were diseased 30 days after inoculation) (38).

Development of the semiselective medium. In order to develop a semiselective medium for culturing $P$. oxalicum isolates, different fungicides and antibiotics were added to MNSM. The MNSM consists of $1.5 \%$ peptone (Difco), $2 \%$ agar (Pronadisa, Madrid, Spain), $0.1 \% \quad \mathrm{KH}_{2} \mathrm{PO}_{4}$ (Panreac Química S.A., Barcelona, Spain), and $0.05 \% \quad \mathrm{MgSO}_{4} \cdot 7 \mathrm{H}_{2} \mathrm{O}$ (Panreac Química S.A.). Following autoclaving, $300 \mathrm{ppm}$ streptomycin (Reig Jofré S.A., Barcelona, Spain), 1:1,000 pentachloronitrobenzene (ChemService Inc., West Chester), and 1 molal $\mathrm{NaCl}$ (Panreac Química S.A.) were added. Using MNSM, we assessed the lycopersici has been tested previously and

sensitivity of PO212 to various fungicides and antibiotics at the following concentrations: $0.2 \mathrm{~g} \mathrm{liter}^{-1}$ chlorothalonil (Comercial Química Massó, Barcelona, Spain), $0.02 \mathrm{~g} \mathrm{liter}^{-1}$ dichloran (Merck-Schuchardt, Hoherbrunn, Germany), 0.5 g liter $^{-1}$ rose bengal (Sigma Chemical Co., St. Louis, MO, USA), $0.001 \mathrm{~g} \mathrm{liter}^{-1}$ amphotericin (Duchefa Biochemie B.V., Haarlem, The Netherlands), $0.006 \mathrm{~g} \mathrm{liter}^{-1}$ nystatin (Roig Farma S.A., TERRASSA, Barcelona, Spain), $0.001 \mathrm{~g} \mathrm{liter}^{-1}$ miconazole nitrate (Panreac Química S.A.), and $0.3 \mathrm{~g} \mathrm{liter}^{-1}$ sorbic acid (GUINAMA S.L.U., Alboraya, Valencia, Spain).

The fungitoxicity of the different culture media was evaluated by assessing the growth of PO212 and one strain of several saprobic and pathogenic fungi that are usually found in soil and are part of our laboratory collection: Penicillium frequentans, $P$. expansum, $P$. purpurogenum, Alternaria spp., F. oxysporum f. sp. lycopersici, Verticillium dahliae, Rhizopus spp., and Aspergillus niger. The isolates of Candida sake and Pichia anomala were kindly provided by I. Viñas (UdL-IRTA, Lleida, Spain). Mycelial plugs $(0.1 \mathrm{~cm}$ diameter) of each fungus were cut from the margins of 7-day-old colonies that were

Table 1. Culture collection number, source, origin, and GenBank accession number of the 14 Penicillium oxalicum strains used in the study

\begin{tabular}{lllll}
\hline Isolate & Culture collection & Source & Origin & $\begin{array}{l}\text { GenBank } \\
\text { accession no. }\end{array}$ \\
\hline PO212 & ATCC 201888 & Soil & Spain & EF103449 \\
PO1 & CBS 300.97 & Soil & Slovenia & EF103450 \\
PO2 & UAMH 5148 & Poultry feed & Australia & EF103451 \\
PO3 & IMI 253788 & Air & Spain & EF103452 \\
PO4 & DAOM 192259 & Foam insulation & Canada & EF103453 \\
PO5 & DAOM 213268 & Stored seeds & Canada & EF103454 \\
PO6 & DAOM 213171 & Cucumber canker & Canada & EF103455 \\
PO7 & DAOM 214729 & Old cucumber roots & Canada & EF103456 \\
PO8 & ATCC 16501 & Soil & Mexico & EF103457 \\
PO9 & ATCC 22095 & Maize & South Africa & EF103458 \\
PO10 & IMI 112755 & Rhizosphere of Vicia faba & Egypt & EF103459 \\
PO11 & IMI 093376 & Rhizosphere of Cicer & India & EF103460 \\
PO12 & CBS 838.96 & Purple Shiso & Netherlands & EF103461 \\
PO13 & $\ldots$ & Stored tobacco & Spain & EF103462 \\
\hline
\end{tabular}

actively growing on PDA. These plugs were transferred to MNSM plates without fungicide or antibiotic (control), and PDA plates and MNSM plates with the different fungicides or antibiotics (test) for further incubation in the dark at 20 to $25^{\circ} \mathrm{C}$ for 10 days. At the end of this incubation, the presence or absence of growth of each fungus in each type of MNSM and PDA plate was recorded. Each fungicide or antibiotic was tested in five PDA plates and five MNSM plates with and without fungicide or antibiotic in at least two separate experiments. Based on the results of this experiment, we selected the best medium for growing $P$. oxalicum.

The fungitoxicity of the selected medium was evaluated also by determining the number of $P$. oxalicum colonies that survived after application of a conidial suspension of $P$. oxalicum to two soil types: sterile peat (Gebr. Brill Substrate $\mathrm{GmbH} \&$ Co. KG, Germany), and natural soil from a site where tomatoes are grown commercially (San Martín de la Vega, Madrid, Spain). Soil samples (200 g) were dried at room temperature, and then sieved through a 2-mm pore-size screen. The peat was sterilized by autoclaving for $1 \mathrm{~h}$ at $121^{\circ} \mathrm{C}$ on three consecutive days, with the samples left at room temperature between each round of autoclaving. Aliquots (10 g) of sterile peat and natural soil were placed in specially designed plastic bags (VALMIC; Sacherei de Pont-Audemer S.A., Pont-Audemer, France). An aliquot of an aqueous conidial suspension of PO212 $\left(10^{8}\right.$ conidia $\mathrm{ml}^{-1}$ ) was applied to sterile and nonsterile soils. The concentration of conidial suspension was determined by counting the number of conidia in a hemacytometer under a light microscope (Zeiss Axioskop 2, Carl Zeiss, Inc., Oberkochem, Germany). The volume of the aliquot was adjusted so that the final conidial densities in the soil were $10^{4}, 10^{5}, 10^{6}$, and $10^{7}$ conidia $\mathrm{g}^{-1}$ of dry soil. Soil moisture content was determined before adding the conidial suspensions, and done by drying 1 -g samples

Table 2. Growth of different microorganisms in modified Nash and Snyder medium (MNSM) supplemented with different fungicides or antibiotics ${ }^{y}$

\begin{tabular}{|c|c|c|c|c|c|c|c|c|}
\hline \multirow[b]{2}{*}{ Microorganisms } & \multicolumn{8}{|c|}{ Fungicides and antibiotics $^{\mathrm{z}}$} \\
\hline & Cl & RB+Dich & Amph & Nyst & SA & MN & MNSM & PDA \\
\hline Penicillium oxalicum & $(+)$ & + & + & + & $(+)$ & + & + & + \\
\hline P. frequentans & - & + & + & - & - & + & + & + \\
\hline P. purpurogenum & - & + & - & - & - & - & - & + \\
\hline P. expansum & - & + & NT & NT & NT & NT & + & + \\
\hline Alternaria spp. & + & + & - & - & - & + & + & + \\
\hline $\begin{array}{l}\text { Fusarium oxysporum } \\
\text { f. sp. lycopersici }\end{array}$ & $(+)$ & + & + & - & - & + & + & + \\
\hline Verticillium dahliae & - & + & - & - & - & + & + & + \\
\hline Rhizopus sp. & - & + & - & - & - & - & - & + \\
\hline Aspergillus niger & - & + & - & - & - & + & - & + \\
\hline Candida sake & - & + & $(+)$ & $(+)$ & - & + & + & + \\
\hline Pichia anomala & NT & NT & + & - & $(+)$ & + & + & + \\
\hline
\end{tabular}

${ }^{\mathrm{y}}+$, Growth; (+), growth slightly suppressed; -, no growth; NT, not tested.

${ }^{\mathrm{z}} \mathrm{Cl}$, chlorothalonil $0.2 \mathrm{~g}$ a.i. liter-1; RB, rose bengal $0.02 \mathrm{~g}$ a.i. liter ${ }^{-1}+$ Dich, dichloran $0.5 \mathrm{~g}$ a.i. liter ${ }^{-1}$; Amph, amphotericin $0.001 \mathrm{~g}$ a.i. liter ${ }^{-1}$; Nyst, nystatin $0.006 \mathrm{~g}$ a.i. liter ${ }^{-1}$; SA, sorbic acid $0.3 \mathrm{~g}$ a.i. liter ${ }^{-1}$; MN, miconazole nitrate $0.0353 \mathrm{~g}$ a.i. liter $^{-1}$; MNSM: Fusarium semiselective medium of Nash and Snyder (34) and modified by De Cal et al. (13); PDA, potato dextrose agar. 
from each bag at $60^{\circ} \mathrm{C}$ until no change in weight was observed. Sterile and nonsterile soil samples that were not treated with PO212 were used as controls. The bags were then sealed, and left at room temperature for 5 to 7 days. Each conidial soil density was tested in duplicate in at least two separate experiments. The density of $P$. oxalicum conidia in the soil was calculated from the number of colony forming units (CFU) per gram of dry soil. In order to count the number of CFU, $5 \mathrm{~g}$ of sterile peat and natural soil samples were placed in 250-ml flasks that contained $100 \mathrm{ml}$ of sterile distilled water. The flasks were then shaken for $30 \mathrm{~min}$ at $150 \mathrm{rpm}$ in a rotary shaker (model 3527; Lab-Line Instruments, Inc., Melrose Park, IL, USA) at room temperature. The washing solutions were collected, and then diluted 10- and 100-fold. Three 100- $\mu$ l aliquots from the diluted washing solutions were spread onto three separate petri dishes that contained either PDA or the selected medium. The plates were then incubated in the dark at $25^{\circ} \mathrm{C}$ for 5 to 7 days, after which the colonies were counted (27).

To evaluate the selectivity of the selected medium, the nonsterile and nontreated soils were washed, and then evaluated in the identical manner, as described above. Upon completion of the incubation, the plates were examined visually and microscopically for the presence of P. oxalicum.

DNA extraction. Total DNA from the mycelia and conidia of each fungal isolate (Tables 1 and 2) was extracted using the DNeasy Plant Mini Kit (Qiagen $\mathrm{GmbH}$, Hilden, Germany) according to the manufacturer's instructions. A 10-mg sample of mycelia and conidia that were grown on PDA at $22^{\circ} \mathrm{C}$ for 7 to 10 days was collected with a spatula, and then transferred into a microfuge tube that contained $400 \mu \mathrm{l}$ of lysis buffer. The DNA from each isolate was eluted into $100 \mu \mathrm{l}$ of sterile water, and its concentration was measured using a SmartSpec Plus spectrophotometer (BioRad Laboratories Ltd., Ontario, Canada). The resultant DNA concentrations ranged

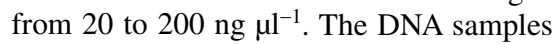
were stored at $-20^{\circ} \mathrm{C}$ until required.

DNA from soil (100 mg) was extracted using the FastDNA Spin Kit for Soil (QBioGene, MP Biomedicals LLC, OH, USA) according to manufacturer's instructions with a modification in the lysis step. The tubes that contained the soil sample and the lysis solution were secured, and then placed in a FastPrep Instrument (MP Biomedicals LLC, OH, USA). Each tube was processed three times consecutively for $1 \mathrm{~min}$ at a speed of $5.5 \mathrm{~m} \mathrm{~s}^{-1}$. The DNA was stored at $-20^{\circ} \mathrm{C}$ until required, and was diluted 1,000-fold prior to PCR.

PCR amplification and sequencing of the ITS regions. The extracted DNA from all the $P$. oxalicum isolates (Table 1) was used as the template for PCR. The primers that were used to amplify the ITS regions were ITS5 (5'-GGAAGTAAAAGTCGT AACAAGG- $\left.3^{\prime}\right)$ and ITS4 (5'-TCCTCC GCTTATTGATATGC-3') (51). The PCRs were performed in a $25-\mu \mathrm{l}$ reaction mixture that contained $10 \mathrm{mM}$ Tris- $\mathrm{HCl}(\mathrm{pH} \mathrm{8.3)}$, $50 \mathrm{mM} \mathrm{KCl}, 100 \mathrm{mM}$ of each dNTP, 2 $\mathrm{mM} \mathrm{MgCl} 2,1 \mathrm{mM}$ of each primer, $1 \mathrm{U}$ of Taq DNA Polymerase (Biotools B\&M Labs, S.A., Madrid, Spain), and $10 \mathrm{ng}$ of template genomic DNA. The PCR conditions were $95^{\circ} \mathrm{C}$ for $3 \mathrm{~min}$, followed by 40 cycles at $95^{\circ} \mathrm{C}$ for $1 \mathrm{~min} 30 \mathrm{~s}, 55^{\circ} \mathrm{C}$ for 1 min, and $72^{\circ} \mathrm{C}$ for $2 \mathrm{~min}$ in an iCycler thermocycler (BioRad Laboratories Ltd.). The reaction was terminated by a final elongation step at $72^{\circ} \mathrm{C}$ for $10 \mathrm{~min}$. Control reactions, in which no DNA template was present, were performed to test for possible contamination of the reagents with fungal DNA. The PCR products were electrophoresed through $1 \%$ agarose gels, stained with ethidium bromide, and then visualized under ultraviolet light. A 1-kb Plus DNA ladder (Invitrogen Life Technologies, Carlsbad, CA, USA) was used as a size marker. All PCRs were repeated at least twice.

The PCR products were purified using the Promega Wizard SV Gel and PCR Clean-up System (Promega, Madison, WI, USA), and then sequenced using the universal primers: ITS1 (5'-TCCGTAGGT GAACTTGCGG-3'), ITS2 (5'-GCTGCG TTCTTCATCGATGC-3'), ITS3 (5'-GCA TCGATGAAGAACGCAGC-3'), and ITS4 (51) on an automated DNA sequencer (ABI 3730, Applied Biosystems, Foster City, CA, USA) at the sequencing services of CISA-INIA (Madrid). The nucleotide sequences of ITS1-5.8S-ITS2 rDNA were aligned and compared using BioEdit Sequence Alignment Editor 5.0.6 (18) and CLUSTAL W 1.82 Program (http://www. clustal.org/) (49). The GenBank accession numbers of the nucleotide sequences from each fungal isolate are given in Table 1 .

In addition to the sequences from the $P$. oxalicum strains listed in Table 1, published nucleotide sequences of ITS1-5.8S-ITS2 rDNA from 11 isolates of $P$. oxalicum were retrieved from GenBank (accession numbers DQ986355, DQ123663, AY213676, AF033438, AF034455, DQ473437, DQ401547, DQ401545, DQ401541, DQ401539, DQ401531) and included in the alignment and comparison of the nucleotide sequences. A dendrogram was constructed by the MEGA program (version 3.1; http://www.megasoftware.net/) (26) using the neighbor-joining method (42) and the Jukes-Cantor model (23). The reliability of the clusters was assessed by bootstrapping with 1,000 replicates (15). Penicillium pinophilum (GenBank accession number AY678604) was used as an outgroup.

Primer design and PCR. Five specific primers for PO212 were designed on the basis of differences in the nucleotide sequences of the ITS1-5.8S-ITS2 region of
PO212 and the other 13 P. oxalicum strains in Table 1 using Primer3 software (http://fokker.wi.mit.edu/primer3/input.htm) (40). The forward primers were named POITS1F $\quad\left(5^{\prime}\right.$-AACCTCCACCCGTGT TTAT- $3^{\prime}$ ) and POITS2F (5'-GTCATTTCT GCCCTCAAGCA-3'), and the reverse primers were named POITS1R (5'-CAG ACAGAGTTCGAGGGTGTC- $3^{\prime}$ ), POIT S2R1 (5'-CCTGGATAAAAATTTGGG TTGA- $3^{\prime}$ ), and POITS2R2 (5'-ATTTGG GTTGATCGGCAAG-3'). Genomic DNA from five isolates of $P$. oxalicum, namely PO212, PO1, PO3, PO13, and PO15 (Table 1), was screened in order to determine the optimal conditions for each forward/ reverse primer combination. The primer combinations tested were POITS1F/ POITS1R, POITS1F/POITS2R1, POITS1F/ POITS2R2, POITS2F/POITS2R1, and POITS2F/POITS2R2. The PCRs were performed in a $25-\mu \mathrm{l}$ reaction volume, and the conditions were identical to those described in the section "PCR amplification and sequencing of the ITS region". Gradient PCRs were performed in order to establish the optimal annealing temperature for each forward/reverse primer combination. The PCR conditions consisted of an initial denaturation step at $95^{\circ} \mathrm{C}$ for $3 \mathrm{~min}$ followed by 40 cycles of denaturation at $95^{\circ} \mathrm{C}$ for $1 \mathrm{~min} 30 \mathrm{~s}$, annealing from 55 to $64^{\circ} \mathrm{C}$ for $1 \mathrm{~min}$, elongation at $72^{\circ} \mathrm{C}$ for 2 min, and a final elongation step of $72^{\circ} \mathrm{C}$ for $10 \mathrm{~min}$. PCR products were electrophoresed through $1 \%$ agarose gels, stained with ethidium bromide, and visualized under ultraviolet light.

Specificity of primers. The specificity of each primer combination was evaluated using the isolated DNA of the 14 strains of P. oxalicum (Table 1) and other fungi in our laboratory collection, namely $P$. frequentans, $P$. expansum, $P$. purpurogenum, Botrytis cinerea, Phoma betae, Epicoccum nigrum, Aspergillus nidulans, Monilinia laxa, Cladosporium cucumerinum, Alternaria spp., Beauveria spp., Beauveria bassiana, Phytophthora cactorum, Verticillium dahliae, Fusarium moniliforme, $F$. oxysporum f. sp. lycopersici, Rhizopus spp., and Metarrhizium anisoplae. The PCR conditions were identical to those described in the section "Primer design and PCR" at different temperatures of annealing (from 63 to $65^{\circ} \mathrm{C}$ ) for each primer pair. Based on the results of these PCRs, a primer pair was selected as the specific primer pair for PO212.

Determination of sensitivity of the PCR with PO212-specific primers. To determine the sensitivity of the PCR with PO212-specific primer POITS1F/POITS2R1,

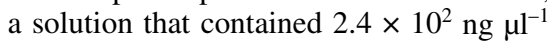
genomic PO212 DNA was diluted serially until the final DNA concentration was 2.4

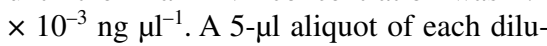
tion was used in the PCR. The PCR conditions were an initial denaturation step at $95^{\circ} \mathrm{C}$ for $3 \mathrm{~min}$ followed by 40 cycles of 
denaturation at $95^{\circ} \mathrm{C}$ for $1 \mathrm{~min} 30 \mathrm{~s}$, annealing at $63.5^{\circ} \mathrm{C}$ for $1 \mathrm{~min}$, elongation at $72^{\circ} \mathrm{C}$ for $2 \mathrm{~min}$, and a final elongation step of $72^{\circ} \mathrm{C}$ for $10 \mathrm{~min}$. The PCR products were electrophoresed through $1 \%$ agarose gels, stained with ethidium bromide, and then visualized under ultraviolet light. The initial DNA concentration of $2.4 \times 10^{2} \mathrm{ng}$ $\mu \mathrm{l}^{-1}$ was measured using a SmartSpec Plus spectrophotometer (BioRad Laboratories).

Detection of PO212 in nonsterile and sterile soil. These assays were performed initially on sterile peat samples that had been watered with purified PO212 DNA, and then repeated on sterile and nonsterile soil samples that were treated with $\mathrm{PO} 212$ conidia.

Firstly, small samples $(100 \mathrm{mg})$ of peat that had been sterilized by autoclaving for 1 $\mathrm{h}$ at $121^{\circ} \mathrm{C}$ on three consecutive days were watered with an aqueous DNA solution that was prepared from the DNA that had been extracted from the mycelia and conidia of PO212. The watering solution comprised DNA that was dissolved in sterile water, and its volume was adjusted so that the DNA concentration was $0.13,1.3$, 13 , and $26 \mathrm{ng}$ of DNA per mg of peat. There were two negative controls: sterile peat that had been watered with DNA extracted from mycelia of PO11 (Table 1), and sterile peat watered with a solution that contained no DNA. The DNA was extracted from each peat sample using the method described in the section "DNA extraction", and then amplified by PCR. The PCR conditions were identical to those described in the section "Determination of sensitivity of the PCR with PO212-specific primers". The experiment was performed twice.

Secondly, the efficiency of the diagnostic procedure was determined in the two soil types that were described in the section "Development of the semiselective medium", namely sterile peat and a natural soil. All soil samples (sterile and nonsterile soil) were then treated with PO212 conidia and left at room temperature for 7 days, as described in the section "Development of the semiselective medium". Upon completion of incubation, DNA was extracted from the soil using the method described in the section "DNA extractions", and then amplified by PCR. The PCR conditions were identical to those described in the section "Determination of sensitivity of the PCR with PO212-specific primers". In addition, the number of PO212 CFU was counted after plating samples of the washing solutions of the experimentally treated soil on the selected medium for growth of PO212. In order to count the number of $\mathrm{CFU}$, each soil sample was processed in the manner described in the section "Development of the semiselective medium". DNA from at least 3\% of the total numbers of colonies that were grown on the selected semiselective medium was extracted using the method described in the section "DNA extraction" from mycelia and conidia, and then amplified using the PCR described in the section "Determination of sensitivity of the PCR with PO212-specific primers". DNA extracted from soil samples that were not inoculated with $\mathrm{PO} 212$ was used as a negative control. DNA extracted from PO212 mycelia was used as a positive control. The experiment was performed twice.

Biocontrol efficacy of $P$. oxalicum strains. Experiments were carried out on tomato plants in growth chambers to compare the biocontrol efficacy of the $P$. oxalicum isolates listed in Table 1. Tomato cultivar San Pedro, which is susceptible to races 1 and 2 of $F$. oxysporum f. sp. lycopersici, was used in all experiments. Tomato seeds were sown in trays $(27 \times 42 \times 7 \mathrm{~cm})$ that contained an autoclaved mixture of vermiculite (Termita; Asfaltex, S.A., Barcelona, Spain) and peat $(1: 1, \mathrm{vol} / \mathrm{vol})$. The trays were maintained in a growth chamber at 22 to $28^{\circ} \mathrm{C}$ with fluorescent lighting $(100 \mu \mathrm{E}$ $\mathrm{m}^{-2} \mathrm{~s}^{-1}, 16-\mathrm{h}$ photoperiod) and 80 to $100 \%$ relative humidity for 4 weeks. Seedlings were watered regularly and treated with an aqueous conidial suspension $\left(1 \times 10^{8}\right.$ conidia $\mathrm{ml}^{-1}$ ) of each $P$. oxalicum strain 7 days before transplanting. Conidia for the treatments were obtained from 14 P. oxalicum strains (Table 1) by incubating PDA plates in the dark at 20 to $25^{\circ} \mathrm{C}$ for 7 days. The volume of the watering solution was adjusted so that it gave a final conidial concentration in the autoclaved vermiculite:peat bed of $6 \times 10^{6}$ conidia per gram of vermiculitepeat mixture. Microconidia of $F$. oxysporum f. sp. lycopersici were produced in 250-ml flasks that contained $150 \mathrm{ml}$ of sterile Czapek Dox broth (Difco). Each flask was inoculated with three mycelial plugs $(1 \mathrm{~cm}$ diameter) of the fungus that was taken from 7-day-old cultures on Czapek Dox agar (CDA) (11). The flasks were incubated for 5 days at $25^{\circ} \mathrm{C}$ in a rotary shaker (model 3527 ; Lab-Line Instruments, Inc.) at $150 \mathrm{rpm}$, and the cultures were then filtered through glass wool. Tomato seedlings (with two true leaves) were transplanted from seedbeds into $100-\mathrm{ml}$ flasks that were filled completely with sterile Hoagland $\mathrm{N}^{\mathrm{o}} 2$ solution (21) so that the roots were in contact with the solution, as described by De Cal et al. (13). Substrate that adhered to the roots was removed gently before placing the plants in the flasks. An aliquot of an aqueous (sterile distilled water) conidial suspension of $F$. oxysporum f. sp. lycopersici was added to the flasks just before transplanting so that the final conidial concentration in the flasks was $1 \times 10^{4}$ conidia $\mathrm{ml}^{-1}$. Plants that had been inoculated with the pathogen, but not treated with $P$. oxalicum, were used as the control. Five replicate flasks, each containing two plants, were used per treatment. The flasks were placed in a randomized complete block design in a growth chamber for $\sim 50$ days under the conditions described earlier in this subsection. The complete experiment was done twice.
Disease severity was graded on days 7 , $15,23,30,38$, and 50 after transplanting on a 1 to 5 index scale: 1,0 to $24 \%$ healthy plants; 2, 25 to $49 \%$ yellow lower leaves; 3, 50 to $74 \%$ dead lower leaves and some yellow upper leaves; 4,75 to $99 \%$ dead lower leaves and wilted upper leaves; and 5, 100\% dead plants (11). The area under the disease progress curve (AUDPC) was calculated (3). All plants were placed in humidity chambers at the end of each experiment, and the presence or absence of the pathogen in the crown after $48 \mathrm{~h}$ incubation at $25^{\circ} \mathrm{C}$ was recorded.

Statistical analysis. Data on the toxicity and selectivity of the new semiselective medium and biocontrol efficacy (AUDPC, disease severity, and disease incidence) were analyzed by analysis of variance. When the $F$ test was significant at $P=$ 0.05 , means were compared by StudentNewman-Keul's multiple range test (46).

\section{RESULTS}

Development of the semiselective medium. Results of the fungitoxicity studies are shown in Table 2. The growth of $P$. purpurogenum, Rhizopus spp., and A. niger were inhibited when they were grown on MNSM only. Chlorothalonil slightly suppressed the growth of $P$. oxalicum and F. oxysporum f. sp. lycopersici, and completely inhibited the growth of all other fungi except for Alternaria spp. The combination of dichloran and rose bengal did not inhibit the growth of any of the microorganisms. The antibiotic amphotericin moderately inhibited the growth of $C$. sake, and completely inhibited the growth of $P$. purpurogenum, Alternaria spp., $V$. dahliae, Rhizopus spp., and A. niger. Amphotericin did not inhibit the growth of $P$. oxalicum, $P$. frequentans, $F$. oxysporum $\mathrm{f}$. sp. lycopersici, and $P$. anomala. Sorbic acid moderately inhibited the growth of $P$. oxalicum and $P$. anomala, and completely inhibited the growth all other fungi. Miconazole nitrate inhibited only the growth of $P$. purpurogenum and Rhizopus spp. Finally, nystatin inhibited growth of all fungi except $P$. oxalicum (Table 2). Based on the results of this experiment, we found that the best semiselective medium for growing $P$. oxalicum contained MNSM plus $0.006 \mathrm{~g}$ liter ${ }^{-1}$ nystatin. This nystatinsupplemented MNSM was selected and named PoIM.

Fungitoxicity and selectivity of PoIM. In order to evaluate the potential toxicity of PoIM, we determined the survival of $P$. oxalicum by applying the conidia to sterile peat, and then incubating the treated peat for 5 to 7 days at room temperature. The numbers of CFU per gram of dry sterile peat on PDA and PoIM were not significantly different $(P=0.05)$ from each other (Table 3).

We evaluated also the potential toxicity of the PoIM after the application of PO212 conidia to sterile and nonsterile soil (Table 
4). The numbers of CFU per gram of sterile peat and natural soil on PoIM were not significantly different $(P=0.05)$ from those counted before the application of PO212 conidia to both soils (Table 4). We found that the population of $P$. oxalicum was higher in sterile soil after application of $\mathrm{PO} 212$ conidia at conidial densities that were $10^{7}$ conidia $\mathrm{g}^{-1}$ dry soil (Table 4 ).

The selectivity of the PoIM was evaluated also by identifying the types of naturally occurring microorganisms in natural soil. While PDA was covered with yeasts, mycelial fungi, and bacteria, PoIM supported only the growth of a few $(<10)$ yeasts and bacteria, and some fungi that were morphologically different from $P$. oxalicum, as well as other Penicillium species (1.7 $\mathrm{CFU} \mathrm{g}^{-1}$ soil).

PCR amplification and sequencing of the $P$. oxalicum ITS region. We amplified and then sequenced the ITS1 and ITS2 regions of the rDNA that included the 5.8S rRNA gene from 14 strains of $P$. oxalicum (Table 1). The size of this region varied from 496 to $502 \mathrm{bp}$ in the 14 strains. The ITS1 data set contained 177 aligned nucleotide positions and 31 variable positions, and the ITS2 data set contained 171 aligned nucleotide positions and 28 variable positions. We found that the mean similarity among all isolates was $96.7 \pm$ 0.4 after a combined analysis of the ITS 1 and ITS2 sequences that included the 5.8S rRNA gene sequence.

These nucleotide sequences were then compared with equivalent sequences from another 11 P. oxalicum strains in the GenBank database. For this purpose, we constructed a dendrogram from the nucleotide sequences of the ITS1, 5.8S, and ITS2 rDNA of the 25 P. oxalicum isolates. Three distinct groups could be identified (Fig. 1). The results of the phylogenetic analysis revealed that most of the $P$. oxalicum strains clustered in one major clade (Group I), with PO4 and PO10 being the most divergent strains in this clade (Group II). PO212 occupied a basal position in the tree (Group III) and was the most divergent of all the $P$. oxalicum strains.

Discrimination of PO212 from other fungal genera by PCR. On the basis of differences in the nucleotide sequences of the ITS1, 5.8S, and ITS2 rDNAs, we designed two forward and three reverse primers for potential use as PO212 strainspecific oligonucleotides. These primers were used in gradient PCRs with DNA from PO212 and the other four P. oxalicum strains, namely PO1, PO3, PO13, and $\mathrm{PO} 15$, as the template. Of the primer pair combinations tested, we found that POITS1F/POITS2R1 is the PO212specific primer pair because a 480-bp product from PO212 DNA was produced by PCR (data not shown) at an annealing temperature of $63.5^{\circ} \mathrm{C}$. This 480 -bp product was not produced from the DNA of the other $P$. oxalicum isolates and the other fungi that are listed in subsection "Specificity of primers" by PCR.

To exclude the possibility that the lack of product was due to the absence of amplifiable DNA, PCRs with universal fungal primers for ITS1 and ITS2 rDNA, namely ITS4 and ITS5 (51), were performed using the PCR described in the section "PCR amplification and sequencing of the ITS region". DNA from all the fungal isolates that are listed in "Specificity of primers" was amplified by PCR with these primers (data not shown). Therefore, we concluded that the absence of DNA in the PCR with these primer pairs was not the reason for not being able to amplify DNA from the fungal isolates.

The sensitivity of the selected primer pair, POITS1F/POITS2R1, was then tested by PCR with each serial dilution of PO212 DNA (Fig. 2). We found that as little as 12 $\times 10^{-2}$ ng of PO212 genomic DNA could be detected with this primer pair (Fig. 2, lane 3).

Detection of PO212 in nonsterile and sterile soil. Experiments were performed to establish the best conditions for detecting PO212 DNA in soil. For this purpose, we did PCR with the selected PO212specific primer pair in order to assess the efficiency and sensitivity of the PCR and the primers. The first set of experiments used DNA that was extracted from 100-mg samples of sterile peat that had been treated with PO212 DNA and then used as a template for the PCR with the selected PO212-specific primer pair (Fig. 3A). The PCR yielded a 480-bp DNA band that contained $\geq 0.13 \mathrm{ng}$ PO212 DNA mg ${ }^{-1}$ soil (Fig. 3A, lane 1). The intensity of the product increased with increasing $\mathrm{PO} 212$ DNA concentrations in sterile peat (Fig. 3A, lanes 1 to 4 ).

The PCR with the selected PO212specific primer pair was capable also of detecting PO212 DNA when the density of PO212 conidia was increased in sterile peat and nonsterile soil (data not shown). The effectiveness of the DNA extraction procedure and the PCR amplification protocol were not influenced by the different composition of the two soil types. Therefore, the PCR can be used for both soil types. For sterile peat, the detection sensitivity was $10^{5}$ conidia $\mathrm{g}^{-1}$ soil (Fig. 3B, lane 2). For nonsterile soil, the detection sensitivity was $10^{6}$ conidia $\mathrm{g}^{-1}$ soil (Fig. 3B, lane 8).

The PO212 strain from sterile peat and nonsterile soil was isolated on PoIM. The DNA extracted from $3 \%$ of the colonies of PO212 that were cultured on PoIM was amplified by PCR with the selected PO212-specific primers. The PCR yielded the expected 480-bp product (gel not shown) in the case of the sterile peat. However, the expected product could not be obtained by PCR with DNA of PO212 from nonsterile soil.

Biocontrol efficacy of $P$. oxalicum strains. All tomato plants (cv. San Pedro) that were inoculated with $F$. oxysporum $\mathrm{f}$. sp. lycopersici showed symptoms of Fusarium wilt. The first symptoms were observed 21 days after inoculation. The incidence of Fusarium wilt was $100 \%$ in the untreated plants 50 days after inoculation. There was a significant reduction in AUDPC, disease severity, and disease incidence following treatment with PO212

Table 3. Number of Penicillium oxalicum CFU per gram of soil on the newly developed semiselective medium, PoIM, and potato dextrose agar (PDA) after application of P. oxalicum strain 212 (PO212) conidia to sterile peat ${ }^{\mathrm{y}}$

\begin{tabular}{lccccc}
\hline & \multicolumn{5}{c}{ Inoculum densities (conidia $\mathbf{g}^{\mathbf{- 1}}$ dry sterile peat) } \\
\cline { 2 - 6 } Media & None & $\mathbf{1 0}^{\mathbf{4}}$ & $\mathbf{1 0}^{\mathbf{5}}$ & $\mathbf{1 0}^{\mathbf{6}}$ & $\mathbf{1 0}^{\mathbf{7}}$ \\
\hline PDA & 0 & $833.3(2.1)$ & $20,500(4.3)$ & $333,333(5.4)$ & $595,000(5.8)$ \\
PoIM & 0 & $2,000(2.8)$ & $22,000(4.3)$ & $365,000(5.5)$ & $1,260,000(6.0)$ \\
MSE $^{z}$ & & $(2.2191) \mathrm{NS}$ & $(0.0331) \mathrm{NS}$ & $(0.10169) \mathrm{NS}$ & $(0.07136) \mathrm{NS}$ \\
\hline
\end{tabular}

${ }^{\mathrm{y}}$ Data are means of two replicates, with three dishes per replicate. Data in parentheses were subjected to $\log _{10} x+1$ transformation to improve the homogeneity of variances before analysis. NS $=$ no significant differences observed in each column.

${ }^{\mathrm{z}}$ Mean squared error of analysis of variance (with transformed data).

Table 4. Number of Penicillium oxalicum CFU per gram of soil on the newly developed semiselective medium, PoIM, after application of P. oxalicum strain 212 (PO212) conidia to sterile and nonsterile soils ${ }^{\mathrm{y}}$

\begin{tabular}{lccccc}
\hline & \multicolumn{5}{c}{ Inoculum densities (conidia $\mathbf{~ g}^{\mathbf{- 1}}$ dry soil) } \\
\cline { 2 - 6 } Media & None & $\mathbf{1 0}^{\mathbf{4}}$ & $\mathbf{1 0}^{\mathbf{5}}$ & $\mathbf{1 0}^{\mathbf{6}}$ & $\mathbf{1 0}^{\mathbf{7}}$ \\
\hline Sterile & $0(0.0) \mathrm{a}$ & $2,000(2.8)$ a & $22,000(4.3) \mathrm{b}$ & $365,000(5.5) \mathrm{a}$ & $1,260,000(6.0) \mathrm{a}$ \\
Nonsterile & $333(1.0) \mathrm{a}$ & $3,000(3.5)$ a & $11,000(4.0)$ a & $305,000(5.5)$ a & $14,566,700(7.1) \mathrm{b}$ \\
MSE $^{z}$ & $(1.20)$ & $(1.0058)$ & $(0.03564)$ & $(0.05379)$ & $(0.07723)$ \\
\hline
\end{tabular}

${ }^{y}$ Data are mean of two replicates, with three dishes per replicate. Data in parentheses were subjected to $\log _{10} x+1$ transformation to improve the homogeneity of variances before analysis. Means followed by the same letter in each column are not significantly different $(P \leq 0.05)$ according to the Student-Newman-Keul's multiple range tests.

${ }^{\mathrm{z}}$ Mean squared error of analysis of variance (with transformed data). 
after 50 days, when compared to untreated plants (Table 5). We observed a significant reduction $(50 \%)$ in disease incidence only, but not the AUDPC and disease severity, in plants that were treated with PO12 when compared to untreated plants (Table 5). We found also no significant reductions in AUDPC, disease severity, and disease incidence in the plants that were treated with the other $P$. oxalicum strains, when compared to untreated plants.

\section{DISCUSSION}

The main practical significance of this work is the development of a strategy to monitor PO212 in the environment when it is used as a BCA. This strategy enables its specific identification by a DNA marker and its quantification using dilution plating on a semiselective medium. Together with the DNA extraction protocol, this monitoring method allows rapid and accurate detection of PO212 in soil.

The classical method for quantifying a particular BCA in an environment consists of counting the number of CFU on a petri dish that contains a selective or semiselec-

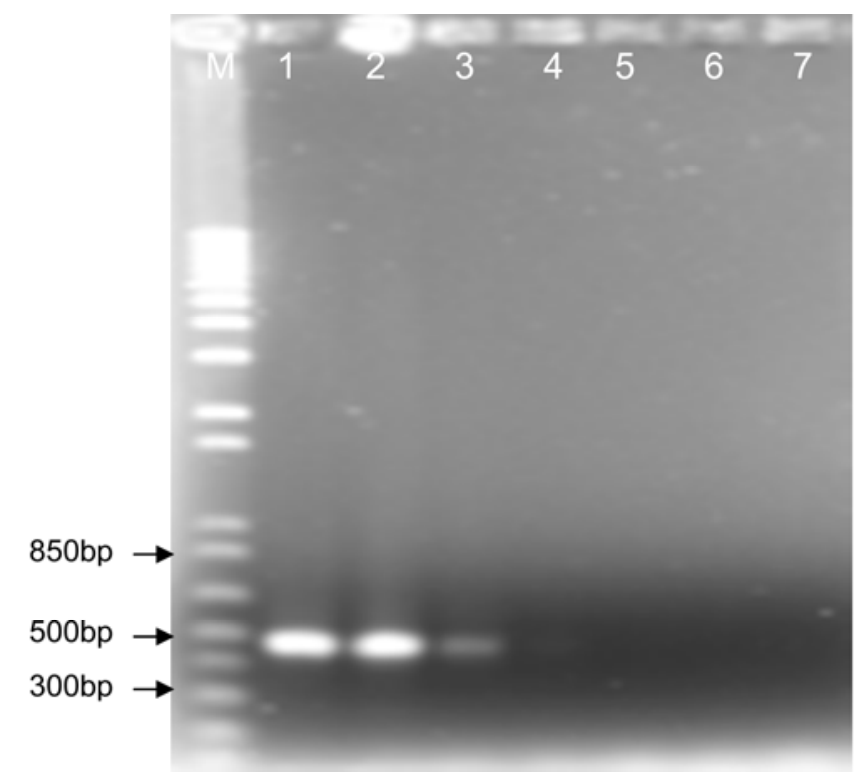

Fig. 2. Polymerase chain reaction amplification in which increasing concentrations of DNA from Penicillium oxalicum strain 212 were used as template with the POITS1F/POITS2R1 primer pair and annealing at $63.5^{\circ} \mathrm{C}$. Lanes 1 to 6 , DNA amplification products with the following concentrations of DNA template: lane $1,1.22 \times 10^{-6} \mathrm{~g}$; lane $2,1.22 \times 10^{-7} \mathrm{~g}$; lane $3,1.22 \times 10^{-8} \mathrm{~g}$; lane $4,1.22 \times 10^{-9} \mathrm{~g}$; lane $5,1.22 \times 10^{-10} \mathrm{~g}$; lane $6,1.22 \times 10^{-11} \mathrm{~g}$. Lane 7, negative control without DNA template. Lane M, molecular weight standard (1-kb Plus DNA Ladder).

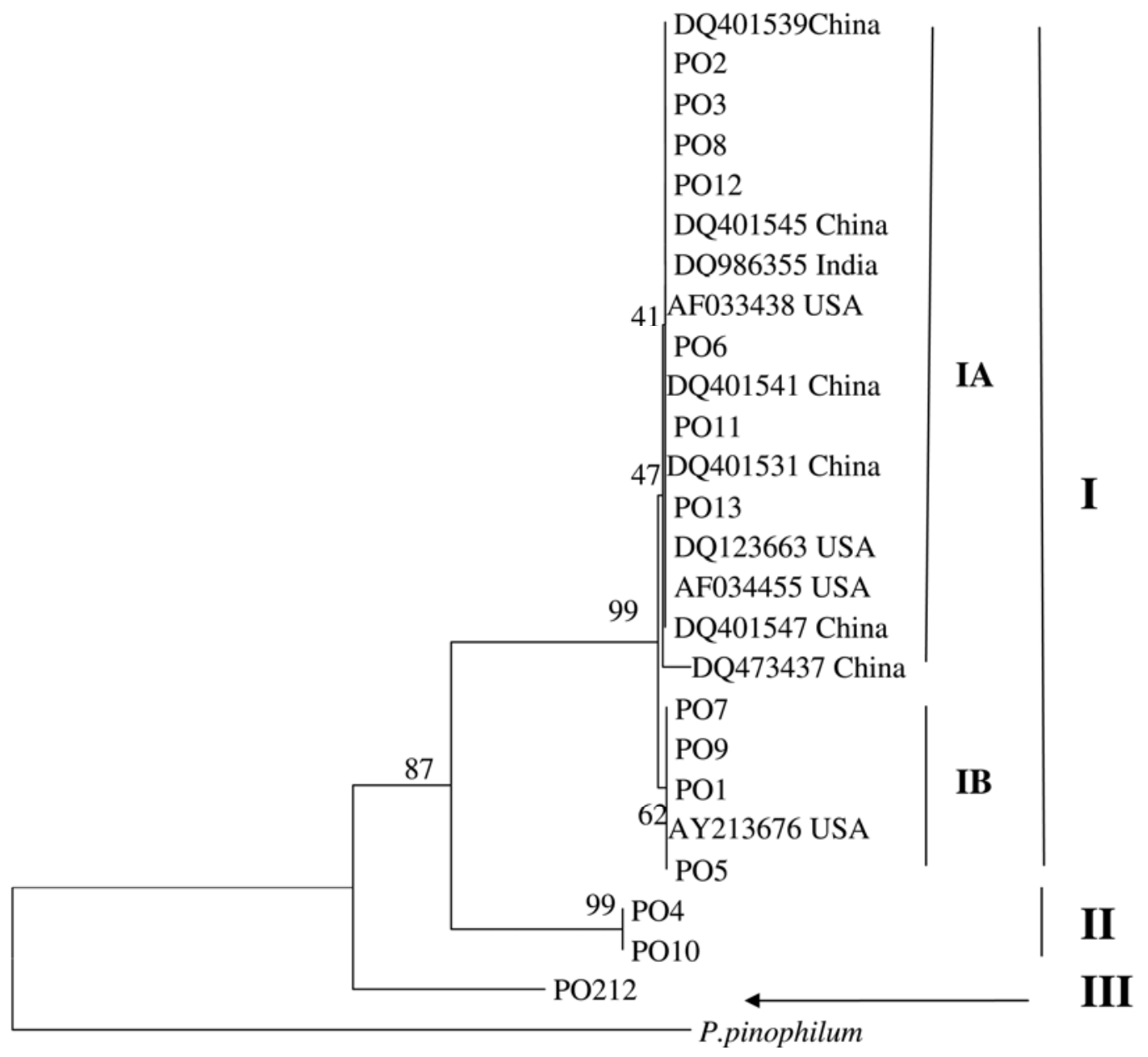

\subsection{2 distances}

Fig. 1. Dendrogram inferred from nucleotide sequences of internal transcribed spacers (ITS) and 5.8 S rRNA (ITS1-5.8S-ITS2). Dendrogram was generated from bootstrapped data sets (15) using the neighbor-joining method (MEGA 3.1; 26). Percentages above branches are frequencies at which a given branch appeared in 1,000 bootstrap replications. Tree was rooted with Penicillium pinophilum (GenBank accession no. AY678604) as an outgroup. 
tive growth medium. This method has the advantage that only living microorganisms are quantified. Although a semiselective medium (MNSM) for detecting and enumerating colonies of $P$. oxalicum from soil and tomato roots has been developed (13), this medium could not distinguish between P. oxalicum and other species of Penicillium. We were able to enhance the selectivity of MNSM by the addition of nystatin (0.006 $\left.\mathrm{g} \mathrm{liter}^{-1}\right)$. This semiselective medium, which we named PoIM, not only permitted growth of $P$. oxalicum, but also allowed $P$. oxalicum to be distinguished from saprophytes, on account of their colony characteristics. Moreover, PoIM was not toxic and showed higher selectivity than the original MNSM for P. oxalicum because we counted similar numbers of CFU on PoIM and PDA.

Unfortunately, the traditional method of counting CFU on a semiselective medium does not distinguish between the BCA and closely related strains or species that may not have the equivalent biocontrol efficacy (39). Therefore, the use of advanced molecular techniques, such as PCR, is required for detection and identification $(8,22)$. For this purpose, strain-specific primers for PCR, which were designed from the nucleotide sequence of the ITS regions of rDNA of the PO212, were used to develop a molecular technique for its environmental detection and identification.

When using PCR to detect fungi, a key step is the method of DNA extraction, or more specifically, the capacity of the method to efficiently extract DNA from hyphae and/or conidia (24). The structure of the fungal cell wall is highly complex and has prevented the development of a universal method for extracting fungal DNA (24). We developed a simple method for extracting DNA from pure fungal cultures in this study. This method not only allows the simultaneous processing of large numbers of samples, but also gives very reproducible DNA for use in PCR. The efficiency of an extraction step is critical when only a minute quantity of fungal material is present in a biological sample. Therefore, the successful detection of microbial DNA in the environment requires its efficient extraction and adequate purification in order to distinguish it from other co-extracted contaminants that have the potential to inhibit PCR $(16,24)$. Our newly developed extraction method is simple and has a small number of efficient lysis and purification steps, which allows rapid processing of many samples. The suitability of this method was confirmed by testing two different types of soil. Soils vary greatly in their chemical and organic composition. They contain also abundant humic substances that inhibit Taq DNA polymerase during PCR (50). In order to minimize the effect of humic substances on PCR, the DNA from soil was diluted 1,000-fold before using it in PCR. Under these conditions, $0.13 \mathrm{ng}$ of PO212 DNA per milligram of sterile soil, or $10^{5}$ and $10^{6}$ conidia per gram of sterile and natural soil, respectively, could be detected by PCR. These results were comparable to those reported in other organisms $(6,45)$. Therefore, this simple and rapid method can be used to provide high quality DNA from $P$. oxalicum in the soil for PCR amplification.

PCR has been proved to be a reliable method for the identification and detection of microorganisms. Specific primers have been designed from ITS regions or rRNA genes of fungi such as Rosellinia (43) or Glomus intraradicis (16). In this work, we found large variations in the nucleotide sequences of the ITS regions of all the studied fungi. The overall range of variation $(<15 \%$ for ITS1 and ITS2 when considered individually, and $<11 \%$ for the total region sequenced) is within the limits of the infraspecific variation that is found for many other fungal species from distinct orders. For instance, Curran et al. (7) found 0 to $12.1 \%$ infraspecific variation in the ITS1 region and 0 to $8.5 \%$ in the ITS2 region of Metarhizium anisopliae, and Neuvéglise et al. (35) reported 0.7 to $18.7 \%$ divergence in the ITS 1 region and 1.8 to $16.7 \%$ in the ITS2 region in Beauveria brogniartii. Less infraspecific divergence has been described for other species such as Trichoderma harzianum, in which a 0 to $2 \%$ variation was reported for ITS 1
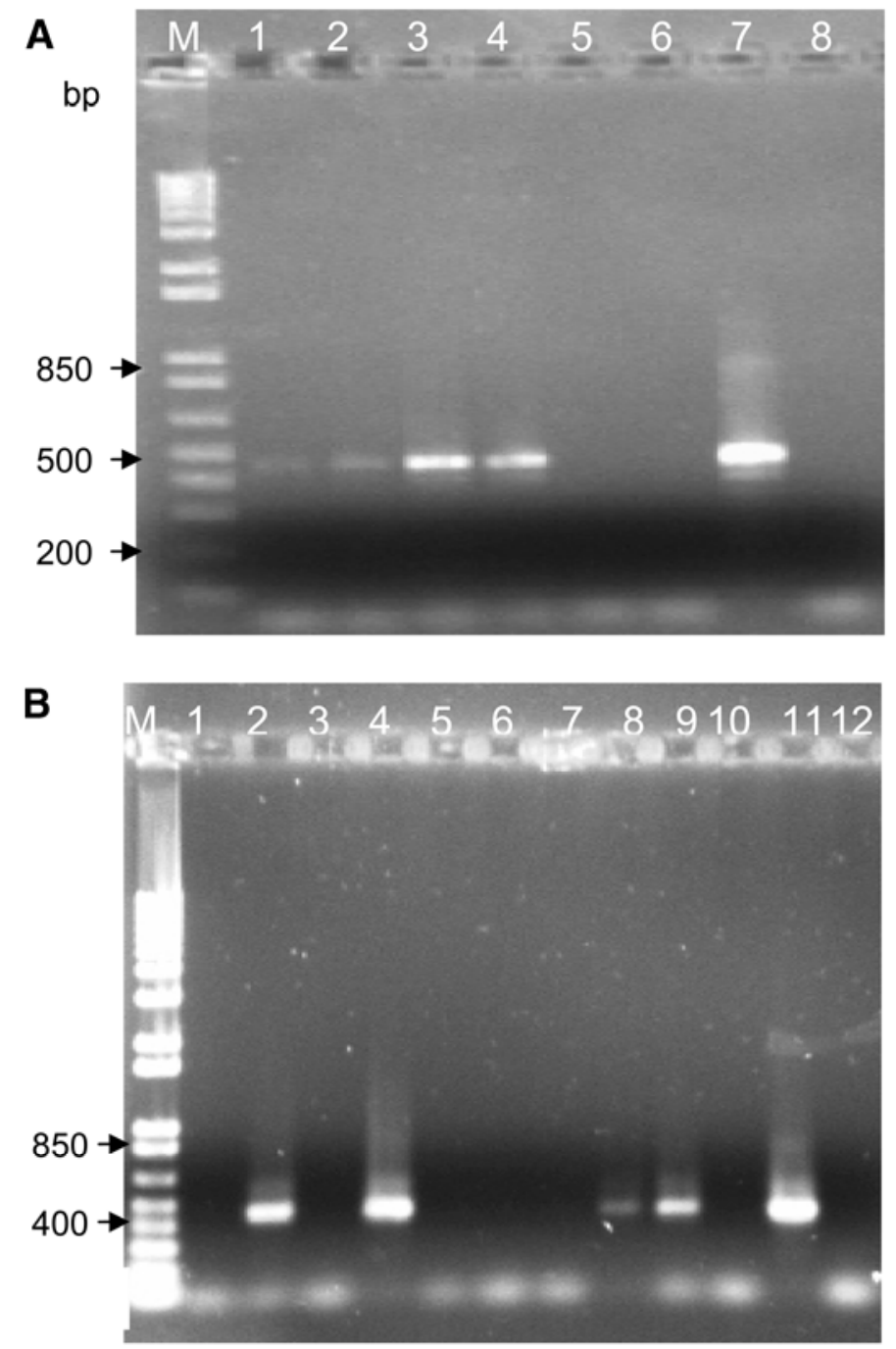

Fig. 3. Detection of DNA from Penicillium oxalicum strain 212 in soil samples by polymerase chain reaction with the POITS1F/POITS2R1 primer pair and annealing at $63.5^{\circ} \mathrm{C}$. A, DNA from sterile peat after watering with four different concentrations of DNA: lane 1, $0.13 \mathrm{ng}$ DNA (mg soil $)^{-1}$; lane 2, 1.3 ng DNA (mg soil) $)^{-1}$; lane 3, 13 ng DNA (mg soil) $)^{-1}$; lane 4, 26 ng DNA (mg soil $)^{-1}$; lane 5, 40 ng DNA (mg soil) $)^{-1}$ from PO11; lane 6, negative control (soil without DNA); lane 7, positive control (DNA extracted from mycelia of PO212); lane 8, negative control without DNA template. B, DNA from sterile peat and no sterile soil after watering with four different concentrations of P. oxalicum 212 conidia. Lanes 1 to 4 correspond to DNA from sterile peat treated with $10^{4}, 10^{5}, 10^{6}$, and $10^{7}$ conidia (g soil) $)^{-1}$, respectively; and lanes 6 to 9 correspond to DNA from nonsterile soil treated with $10^{4}, 10^{5}$, $10^{6}$, and $10^{7}$ conidia (g soil) $)^{-1}$, respectively; lanes 5 and 10 , negative controls (sterile peat and nonsterile soil watered with DNA-free solution, respectively). Lane 11, positive control (DNA extracted from mycelia of the PO212); lane 12, negative control without DNA template; lane M, molecular weight standard (1-kb Plus DNA Ladder). 
(17), and up to $4.6 \%$ variation in the ITS1 region for Phytophthora cinnamomi (30). It has been contended that a single base pair difference in rDNA is sufficient to distinguish between two species (32). We detected many nucleotide substitutions when we aligned and compared the nucleotide sequences of the ITS1 and ITS2 regions of the strains of $P$. oxalicum. This finding contrasts sharply with the observation of a small number of differences in the nucleotide sequences of the ITS regions between Penicillium species (37). However, many nucleotide substitutions in the ITS region have been reported in closely related taxa in Fusarium (36). Despite the presence of 61 nucleotide differences in the ITS region, the $P$. oxalicum strains were almost indistinguishable on the basis of traditional morphological characteristics (data not shown). Of the 61 differences that were found in the 502-bp region, 31 were located in ITS1, and 27 were located in ITS2. We found that the nucleotide sequences in 5.8S rRNA region from the 14 $P$. oxalicum strains were highly conserved, and differed by only two base pairs and a gap.

We found no correlation between infraspecific variation and either the geographical origin or ecological niche of the isolates after phylogenetic analysis of the nucleotide sequences of ITS1-5.8S-ITS2 rDNA. Surprisingly, we found the greatest sequence difference between two isolates from Spain (PO3 and PO212), whereas the most closely related isolates of $P$. oxalicum (PO4 and PO10) were from Canada and Egypt, respectively. A lack of correlation between genetic variation and geographical origin of the isolates has been reported for other fungi, such as Trichoderma (20),
Ampelomyces (47), and even Penicillium strains (44). Strains within one group may have derived from others by asexual propagation (no sexual form of $P$. oxalicum has been reported), and the differences that were observed between strains belonging to the same group may have resulted from mutations or somatic rearrangements. Although the dendrogram did not show a correlation between the distinct groups and their geographical origins, it allowed us to distinguish PO212 from the other strains. Understanding of the nature and diversity of this fungus will be critical for its potential widespread use as a BCA for controlling phytopathogenic fungi. For this reason, there is a pressing need to establish a DNA fingerprint of $P$. oxalicum. In this report, we describe a DNA fingerprint strain 212 of $P$. oxalicum which was based on genetic screening of this fungus. This screening had two steps: identifying the nucleotide sequences of the ITS regions of its rDNA, and then comparing the results of the sequencing with the nucleotide sequences of the ITS regions of rDNA from other P. oxalicum strains. Validation of this screen will need to continue by examining the nucleotide sequences of the ITS regions of rDNA from more strains of $P$. oxalicum, and using other DNA fingerprinting techniques.

In the present work, we designed a primer pair (POITS1F/POITS2R1) based on the nucleotide sequences in the ITS regions of strain PO212 for use in PCR. This primer pair allowed unequivocal detection of a 480-bp single fragment from pure PO212 cultures, and from nonsterile soil that contained DNA from diverse microorganisms. This unequivocal detection of PO212 is supported by the lack of a

Table 5. Effects of different Penicillium oxalicum strains on the AUDPC, disease severity, and disease incidence caused by Fusarium oxysporum f. sp. lycopersici in tomato plants (cv. San Pedro) cultivated in a growth chamber 50 days after inoculation ${ }^{\mathrm{w}}$

\begin{tabular}{lccc}
\hline Treatment $^{\mathbf{x}}$ & AUDPC $^{\mathbf{y}}$ & Disease severity (\%) & Disease incidence (\%) \\
\hline PO212 & $14.3 \mathrm{c}$ & $5.6 \mathrm{~b}$ & $22 \mathrm{c}$ \\
PO1 & $70.2 \mathrm{ab}$ & $30.6 \mathrm{a}$ & $57 \mathrm{ab}$ \\
PO2 & $48.6 \mathrm{~b}$ & $28.1 \mathrm{ab}$ & $88 \mathrm{a}$ \\
PO3 & $59.9 \mathrm{ab}$ & $22.5 \mathrm{ab}$ & $80 \mathrm{ab}$ \\
PO4 & $102.5 \mathrm{a}$ & $42.5 \mathrm{a}$ & $89 \mathrm{a}$ \\
PO5 & $88.8 \mathrm{ab}$ & $42.5 \mathrm{a}$ & $80 \mathrm{ab}$ \\
PO6 & $91.9 \mathrm{ab}$ & $42.5 \mathrm{a}$ & $100 \mathrm{a}$ \\
PO7 & $79.9 \mathrm{ab}$ & $25.0 \mathrm{ab}$ & $91 \mathrm{a}$ \\
PO8 & $68.4 \mathrm{ab}$ & $22.5 \mathrm{ab}$ & $80 \mathrm{ab}$ \\
PO9 & $68.4 \mathrm{ab}$ & $25.0 \mathrm{ab}$ & $70 \mathrm{ab}$ \\
PO10 & $82.5 \mathrm{ab}$ & $32.5 \mathrm{a}$ & $90 \mathrm{a}$ \\
PO11 & $74.9 \mathrm{ab}$ & $35.0 \mathrm{a}$ & $80 \mathrm{ab}$ \\
PO12 & $58.3 \mathrm{ab}$ & $27.5 \mathrm{ab}$ & $50 \mathrm{bc}$ \\
PO13 & $84.0 \mathrm{ab}$ & $42.5 \mathrm{a}$ & $80 \mathrm{ab}$ \\
NT & $77.9 \mathrm{ab}$ & $44.4 \mathrm{a}$ & $100 \mathrm{a}$ \\
MSE $^{z}$ & 988.42 & 692.47 & $2,343.43$ \\
\hline
\end{tabular}

${ }^{\text {w }}$ Data are mean of five flasks with two plants per flask. Means followed by the same letter in each column are not significantly different $(P \leq 0.05)$ according to Student-Newman-Keul's multiple range tests.

${ }^{x}$ Plants were inoculated with $10^{4}$ microconidia per milliliter of $F$. oxysporum f. sp. lycopersici. Treatments were applied 7 days before transplanting with $6 \times 10^{6}$ conidia $\mathrm{g}^{-1}$ seedbed substrate from 14 different strains of P. oxalicum; NT, untreated plants (controls).

${ }^{\mathrm{y}}$ Area under disease progress curve estimated as described in Campbell and Madden (3).

${ }^{\mathrm{z}}$ Mean squared error of analysis of variance. detectable cross-reaction with DNA from taxonomically diverse fungal strains. The specificity of this primer pair in amplifying only DNA from PO212, and not any of the other tested DNA, can be attributed to the large number of mismatches between the sequence of POITS2R1 and DNA of the other tested strains. Of the 22 nucleotides that constituted this primer, variability occurred in 14 positions. In addition, the number of mismatches was higher at the $3^{\prime}$ end of POITS2R1 than in the rest of the sequence ( 9 versus 5). A large number of 3' mismatches between primer and template prevents complete primer annealing to template DNA during PCR, and subsequently inhibits amplification.

Careful design and selection of primers can significantly improve the sensitivity of PCR. In addition, the sensitivity of a PCR assay depends on several factors, of which the most important are the composition and structure of each primer in the primer set and its homology with the target molecule (19). We found that at least $0.12 \mathrm{ng}$ of $P$. oxalicum DNA can be unambiguously detected by PCR with the PO212-specific primer pair, POITS1F/POITS2R1. This set of primers was designed on the basis of its composition, structure, and homology with the target molecule. Moreover, this primer pair was selected from five designed primer pairs after intensive testing.

Although PCR is a sensitive assay, one of its limitations is its inability to differentiate between the DNA of dead and live cells (48). Monitoring methods that combine plating in petri dishes with PCR screening of randomly chosen colonies using classical extraction procedures prior to PCR amplification have already been described $(1,2)$. After plating PO212 on our newly developed semiselective medium, PoIM, we demonstrated that viable PO212 is present after its application to sterile and natural soil. When this plating method was combined with PCR, we were able to identify viable PO212 in the soils. However, the probability of detecting PO212 by PCR in a random sample of soil collected from a field may be relatively low because of the size of the soil sample. The probability will be even lower when testing for the presence of PO212 in randomly collected multiple samples from a field in which its distribution may not be uniform. This limitation needs to be addressed before the method can be employed on a routine basis.

Based on our results from the assays of biocontrol efficacy, we showed that only strain 212 of $P$. oxalicum, and not other $P$. oxalicum strains, could reduce the AUDPC and the disease incidence of Fusarium wilt of tomato. This finding confirms results that have reported previously on Fusarium wilt of tomato in Spain, in which the PO212 isolate showed a strong activity against $F$. oxysporum f. sp. lycopersici and others tomato plant pathogens $(11,28,29)$. 
Although the relationship among isolates that have the same nucleotide sequence in the ITS regions and biocontrol activity is not yet clear, our comparative results do suggest that there is a correlation between the nucleotide sequence in the ITS region and biocontrol activity.

In conclusion, we developed a strategy for the unequivocal detection of the biocontrol strain 212 of $P$. oxalicum in soil samples. We showed that the combined use of a semiselective growth medium, PoIM, with PCR is a useful strategy for detecting and quantifying viable conidia in natural environments. The use of a specific primer pair for strain 212 of $P$. oxalicum enables effective environmental monitoring of the biofungicide and assessment of its impact on the host population structure following its environmental release.

\section{ACKNOWLEDGMENTS}

This work received financial support from AGL2004-02161, RTA2007-00067 (Plan Nacional de I+D+I, Ministerio de Ciencia e Innovación, Spain) and from RC04-3231 (Programa Ramón y Cajal, Ministerio de Ciencia e Innovación, Spain). Special thanks to Antonieta De Cal for her critical review of the manuscript. We thank P. Sabuquillo for providing isolates of $P$. oxalicum and J. Cubero for his assistance with the phylogenetic analysis. We also thank Y. Herranz for technical support.

\section{LITERATURE CITED}

1. Abbasi, P. A., Miller, S. A., Meulia, T., Hoitink, H., and Kim, J.-M. 1999. Precise detection and tracing of Trichoderma hamatum 382 in compost-amended potting mixes by using molecular markers. Appl. Environ. Microbiol. 65:5421-5426.

2. Atkins, S. D., Clark, I. M., Sosnowska, D., Hirsch, P. R., and Kerry, B. R. 2003. Detection and quantification of Plectosphaerella cucumerina, a potential biological control agent of potato cyst nematodes, by using conventional PCR, real-time PCR, selective media, and baiting. Appl. Environ. Microbiol. 69:4788-4793.

3. Campbell, C. L., and Madden, L. V., eds. 1990. Introduction to Plant Disease Epidemiology. Wiley-Interscience, New York.

4. Cappa, F., and Cocconcelli, P. S. 2001. Identification of fungi dairy products by means of $18 \mathrm{~S}$ rRNA analysis. Int. J. Food Microbiol. 69:157-160.

5. Cook, R. J. 2000. Advances in plant health management in the 20th century. Annu. Rev. Phytopathol. 38:95-116.

6. Cullen, D. W., and Hirsch, P. R. 1998. Simple and rapid method for direct extraction of microbial DNA from soil for PCR. Soil Biol. Biochem. 30:983-993.

7. Curran, J., Driver, F., Ballard, J. W. O., and Milner, R. J. 1994. Phylogeny of Metarhizium, analysis of ribosomal DNA sequence data. Mycol. Res. 98:457-552.

8. Dean, T. R., Kohan, M., Betancourt, D., and Menetrez, M. Y. 2006. A simple polymerase chain reaction-sequencing analysis capable of identifying multiple medically relevant filamentous fungal species. Mycopathologia 162:265-271.

9. De Cal, A., García-Lepe, R., and Melgarejo, P. 2000. Induced resistance by Penicillium oxalicum against Fusarium oxysporum f. sp. lycopersici: Histological studies of infected and induced tomato stems. Phytopathology 90:260-268.

10. De Cal, A., García-Lepe, R., Pascual, S., and Melgarejo, P. 1999. Effects of timing and method of application of Penicillium oxalicum on efficacy and duration of control of Fusarium wilt of tomato. Plant Pathol. 48:260-266.

11. De Cal, A., Pascual, S., and Melgarejo, P. 1995. Biological control of Fusarium oxysporum $\mathrm{f}$. sp. lycopersici. Plant Pathol. 44:909-914.

12. De Cal, A., Pascual, S., and Melgarejo, P. 1997. Involvement of resistance induction by Penicillium oxalicum in the biocontrol of tomato wilt. Plant Pathol. 46:72-79.

13. De Cal, A., Pascual, S., and Melgarejo, P. 1997. Infectivity of chlamydospores vs microconidia of Fusarium oxysporum f. sp. lycopersici on tomato. J. Phytopathol. 145:231-233.

14. De Cal, A., Redondo, C., Sztejnberg, A., and Melgarejo, P. 2008. Biocontrol of powdery mildew by Penicillium oxalicum in open-field nurseries of strawberries. Biol. Control 47:103-107.

15. Felsenstein, J. 1985. Confidence limits on phylogenies, an approach using the bootstrap. Evolution 39:783-791.

16. Filion, M., St-Arnau, M., and Jabaji-Hare, S. H. 2003. Direct quantification of fungal DNA from soil substrate using real-time PCR. J. Microbiol. Methods 1735:1-10.

17. Grondona, I., Hermosa, R., Tejada, M., Gomis, M. D., Mateos, P. F., Bridge, P. D., Monte, E., and García-Acha, I. 1997. Physiological and biochemical characterization of Trichoderma harzianum, a biological control agent against soilborne fungal plant pathogens. Appl. Environ. Microbiol. 63:3189-3198.

18. Hall, T. A. 1999. BioEdit: A user-friendly biological sequence alignment editor and analysis program for Windows 95/98/NT. Nucleic Acids Symp. Ser. 41:95-98.

19. He, Q., Marjamaki, M., Soini, H., Mertsola, J., and Viljanen, M. K. 1994. Primers are decisive for sensitivity of PCR. BioTechniques 17:8287.

20. Hermosa, M. R., Keck, E., Chamorro, I., Rubio, B., Sanz, L., Vizcaíno, J. A., Grondona, I., and Monte, E. 2004. Genetic diversity shown in Trichoderma biocontrol isolates. Mycol. Res. 108:897-906.

21. Hoagland, D. R., and Arnon, D. I. 1950. The water-culture method for growing plants without soil. Calif. Agric. Exp. Stn. Circ. 347.

22. Isik, N., White, L., Barnes, R., Poynton, C. J., and Mills, K. I. 2003. A simple PCR/RFLP analysis can differentiate between Candida albicans, Aspergillus niger, and Aspergillus fumigatus. Mol. Biotechnol. 24:229-232.

23. Jukes, T. H., and Cantor, C. R. 1969. Evolution of protein molecules. Pages 21-132 in: Mammalian Protein Metabolism. H. N. Munro, ed. Academic Press, New York.

24. Karakousis, A., Tan, L., Ellis, D., Alexiou, H., and Wormald, P. J. 2006. An assessment of the efficiency of fungal DNA extraction methods for maximizing the detection of medically important fungi using PCR. J. Microbiol. Methods 65:38-48.

25. Knight, I. T. 2000. Molecular genetic methods for detection and identification of viable but nonculturable microorganisms. Pages 77-85 in: Nonculturable Microorganisms in the Environment. R. R. Colwell and D. J. Grimesa, eds. ASM Press, Washington, DC

26. Kumar, S., Tamura, K., and Nei, M. 2004. Integrated software for Molecular Evolutionary Genetic Analysis and sequence alignment. Brief Bioinform. 5:150-163.

27. Lacey, J., Hill, S. T., and Edwards, M. A. 1980. Microorganisms in stored grains: Their enumeration and significance. Trop. Stor. Prod. Inf. 39:19-33

28. Larena, I., De Cal, A., García-Lepe, R., and Melgarejo, P. 2001. Biocontrol of tomato diseases by Penicillium oxalicum. Pages 387-394 in: Modern Fungicides and Antifungal Compunds, III. H.-W. Dehne, U. Gisi, K. H. Kuck, P. E. Russell, and H. Lyr, eds. AgroConcept Gmbh, Bonn

29. Larena, I., Sabuquillo, P., Melgarejo, P., and De
Cal, A. 2003. Biocontrol of Fusarium and Verticillium wilt of tomato by Penicillium oxalicum under greenhouse and field conditions. J. Phytopathol. 151:507-511.

30. Lee, S. B., and Taylor, J. W. 1992. Phylogeny of five fungus-like protoctistan Phytophthora species, inferred from the internal transcribed spacers of ribosomal DNA. Mol. Biol. Evol. 9:636-653.

31. Lindow, S. E., and Brandl, M. T. 2003. Microbiology of the phyllosphere. Appl. Environ. Microbiol. 69:1875-1883.

32. Logrieco, A., Peterson, S. W., and Wicklow, D. T. 1990. Ribosomal RNA comparisons among taxa of the terverticillate penicillia. Pages 343 355 in: Modern Concepts in Penicillium and Aspergillus Systematics. R. A. Samson and J. I. Pitt, eds. Plenum Press, New York.

33. Montesinos, E. 2003. Development, registration and commercialization of microbial pesticides for plant protection. Int. Microbiol. 6:245-252.

34. Nash, S. M., and Snyder, W. C. 1962. Quantitative estimation by plate counts of propagules of the bean root rot Fusarium in fields soils. Phytopathology 52:567-572.

35. Neuvéglise, C., Brygoo, Y., Vercambre, B., and Riba, G. 1994. Comparative analysis of molecular and biological characteristics of strains of Beauveria brongniartii isolated from insects. Mycol. Res. 98:322-328.

36. O'Donnell, K. 1992. Ribosomal DNA internal transcribed spacers are highly divergent in the phytopathogenic ascomycete Fusarium sambucinum (Gibberella pulicaris). Curr. Genet. 22:213-220.

37. Peterson, S. W. 1993. Molecular genetic assessment of relatedness of Penicillium subgenus Penicillium. Pages 121-128 in: The Fungal Holomorph: Mitotic, Meiotic and Pleomorphic Speciation in Fungal Systematics. D. R. Reynolds and J. W. Taylor, eds. CAB, Wallingford, UK.

38. Pineau, R. 1976. Etude sur les Tracheomycoses de la Tomate au Maroc. Ph.D. thesis. Universite Nancy, Nancy, France.

39. Pujol, M., Badosa, E., Manceau, Ch., and Montesinos, E. 2006. Assessment of the environmental fate of the biological control agent of fire blight, Pseudomonas fluorescens EPS62e, on apple by culture and real-time PCR methods. Appl. Environ. Microbiol. 72:2421-2427.

40. Rozen, S., and Skaletsky, H. J. 2000. Primer3 on the WWW for general users and for biologist programmes. Pages 365-386 in: Bioinformatics Methods and Protocols: Methods in Molecular Biology. S. Krawetz and S. Misener, eds. Human Press, Totova, NJ

41. Sabuquillo, P., De Cal, A., and Melgarejo, P. 2005. Dispersal improvement of a powder formulation of Penicillium oxalicum, a biocontrol agent of tomato wilt. Plant Dis. 89:13171323 .

42. Saitou, N., and Nei, M. 1987. The neighborjoining method: A new method for reconstructing phylogenetic trees. Mol. Biol. Evol. 4:406425.

43. Schena, L., Nigro, F., and Ippolito, A. 2002. Identification and detection of Rosellinia necatrix by conventional and real-time PCR. Eur. J. Plant Pathol. 108:355-366.

44. Sequerra, J., Marmeisse, R., Valla, G., Normand, P., Capellano, A., and Moiroud, A 1997. Taxonomic position and intraspecific variability of the nodule forming Penicillium nodositum inferred from RFLP analysis of the ribosomal intergenic spacer and random amplified polymorphic DNA. Mycol. Res. 101:465472.

45. Smalla, K., Cresswell, N., and MendoncaHagler, L. C. 1993. Rapid DNA extraction protocol from soil for polymerase chain reactionmediated amplification. J. Appl. Bacteriol. 
74:78-85.

46. Snedecor, G. W., and Cochran, W. G. 1980. Statistical Methods. 7th ed. Iowa State University, Ames.

47. Szentiványi, O., Kiss, L., Russell, J. C., Kovács, G. M., Varga, K., Jankovics, T., Lesemann, S., Xu, X.-M., and Jeffries, P. 2005. Ampelomyces mycoparasites from apple powdery mildew identified as a distinct group based on single-stranded conformation polymorphism analysis of the rDNA ITS region. Mycol. Res. 109:429-438.
48. Taylor, G., Wang, X., and Jabaji-Hare, S. H. 2003. Detection of the mycoparasite Stachybotrys elegans, using primers with sequencecharacterized amplification regions in conventional and real-time PCR. Can. J. Plant Pathol. 25:49-61.

49. Thompson, J. D., Higgins, D. G., and Gibson, T. J. 1994. CLUSTAL W: Improving the sensitivity of progressive multiple sequence alignment through sequence weighting, positionspecific gap penalties and weight matrix choice. Nucleic Acids Res. 22:4673-4680.
50. Tsai,Y.-L., and Olson, B. H. 1992. Rapid method for separation of bacterial DNA from humic substances in sediments for polymerase chain reaction. Appl. Environ. Microbiol. 58:2292-2295.

51. White, T. J., Bruns, T. D., Lee, S., and Taylor, J. 1990. Amplification and direct sequencing of fungal ribosomal genes for phylogenetics. Pages 315-322 in: PCR Protocols: A Guide to Methods and Applications. M. A. Innis, D. H. Gelfand, J. J. Sninsky, and T. J. White, eds Academic Press, San Diego. 